\title{
Multidisciplinary program for stress-related disease in primary health care
}

\author{
This article was published in the following Dove Press journal: \\ Journal of Multidisciplinary Healthcare \\ 5 May 2009 \\ Number of times this article has been viewed
}

\author{
Eva Ekvall Hansson' \\ Eva Håkansson ${ }^{2}$ \\ Annelie Raushed ${ }^{2}$ \\ Anders Håkansson' \\ 'Lund University, Department \\ of Clinical Sciences in Malmö/General \\ Practice, Malmö, Sweden; ${ }^{2}$ Primary \\ Health Care Malmö, Sweden
}

Objective: To describe a multidisciplinary program, given by an occupational therapist and a physiotherapist, for patients with stress-related disease in primary health care and to measure the effect of this program in terms of self-perceived health, degree of burnout, physical activity, symptoms, recreational activities, and psychological and physical well-being.

Method: Retrospective study.

Results: At measures after three months, the thirteen patients included in this study had improved in self-estimated health, measured with EuroQol-5D Visual Analogue Scale ( $p=0.000)$, and in degree of burnout, measured with the Shirom-Melamed Burnout Questionnaire ( $p=0.001)$. There was also a decrease in presence of headache, in physical activity and in satisfaction with leisure time, although not statistically significant. After six months, the improvements remained for all measures except physical activity. The patients were also satisfied with the program to a high degree, measured with Client Satisfaction Questionnaire (median 3.7).

Conclusion: This descriptive study shows that a stress-management program, provided by a team including an occupational therapist and a physiotherapist in primary health care, is both feasible and effective in terms of self-estimated health, degree of burnout, and patient satisfaction.

Keywords: stress-related health, burnout, occupational therapy, physiotherapy

\section{Introduction}

There has been a dramatic increase of long-term sick-listing in Sweden in the last ten years, probably a result of the increase of mental disorder in the community. ${ }^{1}$ Psychological stress related to job situation, often referred to as burnout, is a major problem in society. ${ }^{2}$ Situations due to different lifestyles also play an important part in causing burnout, as does the increase of information we are surrounded by and how we prioritize between different activities. ${ }^{3}$ Burnout can also be a risk factor for other diseases, such as cardiovascular disease. ${ }^{4}$ Women often share their time between job and family, which can be one reason for the increase in stress-related mental illness among women. ${ }^{5}$ To benefit health and well-being, a satisfactory balance across the occupational performance areas of self-care, productivity, and leisure seems beneficial. $^{6}$

Sleep is important to help the nervous system, the endocrine system and the immune system to maintain the delicate balance that keeps us healthy. ${ }^{7}$ Disturbances in sleep may facilitate burnout, through the effect on the immune system. ${ }^{8}$

Relaxation therapy has proved to be an important tool for patients with burnout. Research has shown effects on various stress-related symptoms, such as blood pressure and muscle tension. ${ }^{9}$ There are different ways to achieve relaxation. Some methods
Correspondence: Eva Ekvall Hansson Lund University, Department of Clinical Sciences in Malmö/General Practice, Entrance 72:28:I I, Malmö University Hospital, 20502 Malmö, Sweden Email eva.ekvall-hansson@med.lu.se 
focus on muscles and being aware of the difference between a tense muscle and a relaxed muscle. Other techniques focus on the mental part of relaxation, for example by repeating a word or a sound or focusing on breathing. ${ }^{10}$

Physical activity reduces mental distress as well as tonic activity from the sympathetic nervous system, and also reduces anxiety and increases well-being through the secretion of endorphins. ${ }^{11}$ Physical activity can therefore affect burnout in terms of increased self-esteem, increased sleep quality, increased creativity as well as decrease in muscle tension. A balanced structure for daily activities appears to be essential. ${ }^{12}$ It therefore seems important to increase the patient's ability to reduce the total load of activities and at the same time introduce physical activity.

Primary health care seems to be the appropriate level of medical care for patients with burnout, and different programs for treating patients with burnout are being used. The aim of this study is to describe and measure the effect of one such program for patients with burnout, treated in primary health care in Malmö, Sweden. We also wanted to find out how satisfied the patients were with the program.

\section{Method}

Malmö is the third largest city in Sweden with almost 300,000 inhabitants. There are 20 different primary health care centers in Malmö that supply primary health care for persons living in each respective catchment areas. Kirseberg's primary health care center has a catchment area of about 14,000 persons and Husie's health care center has a catchment area of about 18,000 persons. The physiotherapist (PT) and occupational therapist (OT) at Kirseberg has specialized in the treatment of patients with burnout and provide treatment for patients referred from the Kirseberg and Husie primary health care centers.

Data were compiled from medical records of patients with burnout, referred to PT and OT, and treated with the program described below. All patients had prolonged response to stressors and their symptoms included the three dimensions of exhaustion, cynicism, and inefficacy. ${ }^{13}$ Patients between 18 to 65 years old were included.

\section{Measurements}

At baseline, all patients filled out a questionnaire about physical activity, symptoms, recreational activities, and psychological and physical well-being.

To measure self-perceived health, the EuroQol-5D Visual Analogue Scale (EQ-5D VAS) was used. ${ }^{14}$ In EQ-5D VAS, patients estimate their health by drawing a line on a scale from 0 to 100 , where 100 is best imaginable health and 0 the worst.

To measure degree of burnout, the Shirom-Melamed Burnout Questionnaire (SMBQ) was used. ${ }^{15}$ SMBQ is a questionnaire with 22 items, graded from 1 (almost never) to 7 (almost always). The mean of the total index, SMBQ-global, was calculated. The lower the value, the better the health.

The same questionnaires were then used at follow-up after three and six months.

To measure how satisfied the patients were with the program, the Client Satisfaction Questionnaire (CSQ) was used. ${ }^{16} \mathrm{CSQ}$ is a questionnaire with eight questions that the patient fills in anonymously. The answers are on a fourpoint categorical Likert scale, where 1 and 2 indicate low satisfaction, 3 indicates good satisfaction, and 4 the highest satisfaction.

\section{Intervention}

The intervention consisted of a program with a cognitive behavioral approach at eighteen individual sessions, once a week for 45 minutes, with either PT or OT. Joint assessment with both PT and OT was performed at the first session, the last session and at follow-up after three and six months. The program is described in detail in Table 1.

\section{Ethics}

All measures used in this study are used routinely by PTs and OTs working with the program. Information was gained retrospectively from these assessments.

\section{Statistics}

Since the sample size was small, the difference between baseline and after three and six months was calculated with Friedman's test regarding EQ5D and SMBQ. Differences regarding physical activity, sick leave, headache, and leisure time were calculated with Sign test.

\section{Results}

Thirteen patients were included in the study, 10 women and three men (median age 40, range 29 to 59). In the group, 11 were employed, one was studying, and one was unemployed. Baseline data for the group are shown in Table 2, as well as differences between baseline and measures at three and six months. After three months, the group had improved in all measurements, statistically significant in EQ5D VAS and SMBQ. At measures after six months, the improvements were the same, except for physical activity. 
Table I The intervention program

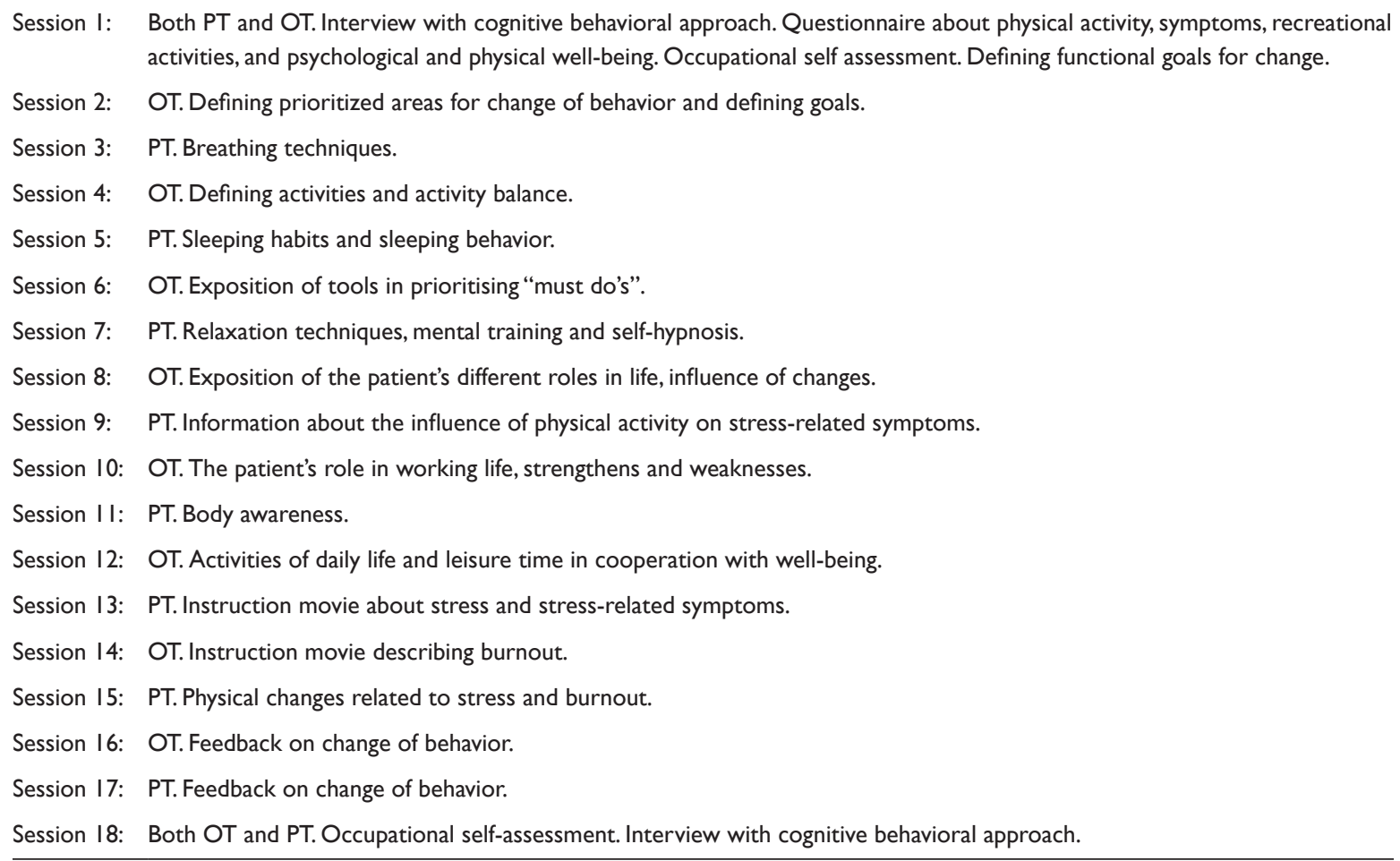

The median score on CSQ was 3.7, range 2.4-4, indicating that the patients were satisfied with the intervention to a high degree.

\section{Discussion}

This small study showed statistically significant improvements in self-estimated health, measured with VAS, and in degree of burnout, measured with SMBQ. At measures after three months, there was a tendency towards improvements in physical activity, in the occurrence of headache and in satisfaction with leisure time, although not statistically significant. These improvements were the same after six months for all measures except physical activity. The study also shows that this type of program for management of stress-related disease is feasible to perform in primary health care.

Since the sample size is small, it is hard to make generalizations about the program in wider terms. Also, we used a retrospective method without a control group and randomization, since we found it hard to motivate a study with prospective approach with a control group consisting of our own patients who, in that case, would have had to wait for six months before treatment. We tried to identify a control group with the same diagnoses through the social insurance office, but this proved to be impossible. The problem of finding a control group is often encountered in clinical research performed by physiotherapists and occupational therapists.

Other studies have found a decrease in sick leave after similar stress-management programs. ${ }^{17,18}$ The improvements in this study in sick leave were that a few patients went from sick leave on $25 \%$ of the day to no sick leave at all. In Sweden it is possible to be on sick leave for part of the day, which might not be used in general in other countries.

The stress management program in our study is quite extensive with 16 individual sessions with either OT or PT and two sessions with both OT and PT. Each session lasted for 45 minutes. In primary health care in Sweden, the average salary is about 25,000 Swedish kronor per month for OT and PT. Calculating on 15 minutes preparation time for each session, this gives a cost of 4500 Swedish kronor per patient for the whole program. So, even if the program seems timeconsuming, it is a cost-effective treatment.

At baseline, the median score for SMBQ were similar to mean score of SMBQ found in a larger population of patients with burnout from Umeå. ${ }^{19}$ At measures after three and six months, the median score in our study were similar to those of a general population. ${ }^{19}$

Pain has been identified as a factor related to burnout among women ${ }^{18}$ as well as having few leisure occupations. ${ }^{20}$ 
Table 2 Baseline data, changes from baseline to three and six months

\begin{tabular}{|c|c|c|c|c|c|}
\hline & \multirow{2}{*}{$\begin{array}{l}\text { Baseline } \\
\mathbf{n}=13\end{array}$} & \multicolumn{2}{|c|}{ Three months } & \multicolumn{2}{|c|}{ Six months } \\
\hline & & $n=13$ & p-value & $n=13$ & p-value \\
\hline Women/men & $10 / 3$ & & & & \\
\hline Age (median) & 40 & & & & \\
\hline SMBQ (median) & 5 & 2.8 & 0.001 & 2.8 & 0.001 \\
\hline EQ5DVAS (median) & 50 & 80 & 0.000 & 85 & 0.000 \\
\hline Sick leave yes/no & $6 / 7$ & $4 / 9$ & 0.5 & $4 / 9$ & 0.5 \\
\hline $\begin{array}{l}\text { Extent of sick leave } \\
(100 / 50 / 25 / 0 \%)^{*}\end{array}$ & \multicolumn{4}{|c|}{$(100 / 50 / 25 / 0 \%)^{*}$} & \\
\hline Headache yes/no & $10 / 3$ & $7 / 6$ & 0.12 & $6 / 7$ & 0.12 \\
\hline Frequency of headache & $(0 / 4 / 2 / 4 / 3)$ & $(0 / 2 / 3 / 2 / 6)$ & & $(0 / 0 / 4 / 3 / 6)$ & \\
\hline \multicolumn{6}{|c|}{ (Very often/often/sometimes/seldom/never) } \\
\hline Satisfied with leisure time yes/no & $6 / 7$ & $10 / 3$ & 0.21 & $10 / 3$ & 0.21 \\
\hline Physical activity yes/no ${ }^{\dagger}$ & $6 / 7$ & $\mathrm{II} / 2$ & 0.06 & $7 / 6$ & 1.00 \\
\hline
\end{tabular}

Notes: *Extent of sick leave $100 \%$ means that the patient is on sick leave for the whole day, $50 \%$ that the patient work half the day and is on sick leave half the day, $25 \%$ means that the patient works $75 \%$ of the day and is on sick leave for $25 \%$, and $0 \%$ means that the patient works full time. 'Physical activity 'yes' means physical activity more than a couple of times per week.

Abbreviations: EQ-5DVAS, EuroQol-5D visual analogue scale; SMBQ, shirom-melamed burnout questionnaire.

We therefore suspect that our findings about increase in physical activity and increase in satisfaction with leisure time are clinically important, although not statistically significant.

Stress-management programs have been shown to be important for patients with burnout, to help them to regain balance in both mind and body. ${ }^{21}$ Our study supports these findings.

\section{Conclusion}

This retrospective study shows that a stress-management program, provided by a team including an occupational therapist and a physiotherapist in primary health care, is both feasible and effective in terms of self-estimated health, degree of burnout, and patient satisfaction.

\section{Disclosure}

The authors report no conflicts of interest in this work.

\section{References}

1. Försäkringskassan. Newly granted sick-leave/compensation for activity. Distribution per county and diagnoses, 2006. (Swedish). Malmö: Försäkringskassan; 2007.

2. Michie S, Williams S. Reducing work related psychological ill health and sickness absence: a systematic literature review. Occup Environ Med. 2003;60(1):3-9.

3. Hakansson C, Dahlin-Ivanoff S, Sonn U. Achieving balance in everyday life:Insights from women with stress.related disorders. J Occup Sci. 2006;13:74-82.

4. Melamed S, Kushnir T, Shirom A. Burnout and risk factors for cardiovascular diseases. Behav Med. 1992;18(2):53-60.
5. Krantz G, Ostergren PO. Double exposure. The combined impact of domestic responsibilities and job strain on common symptoms in employed Swedish women. Eur J Public Health. 2001;11(4): 413-419.

6. Backman CL. Occupational balance: exploring the relationships among daily occupations and their influence on well-being. Can J Occup Ther. 2004;71(4):202-209.

7. Moldofsky H. Sleep and the immune system. Int J Immunopharmacol. 1995;17(8):649-654.

8. Born J, Lange T, Hansen K, Molle M, Fehm HL. Effects of sleep and circadian rhythm on human circulating immune cells. J Immunol. 1997;158(9):4454-4464.

9. Shirom A, Westman M, Shamai O, Carel RS. Effects of work overload and burnout on cholesterol and triglycerides levels: the moderating effects of emotional reactivity among male and female employees. J Occup Health Psychol. 1997;2(4): 275-288.

10. Blomberg M. [Training for improved body awareness and relaxation for stress management]. Lakartidningen. 2004;101(15-16): 1398-1400.

11. Salmon P. Effects of physical exercise on anxiety, depression, and sensitivity to stress: A unifying theory. Clin Psych Rev. 2001;21: $35-61$.

12. Socialstyrelsern. Burnout. Stressrelated mental disorder. (In Swedish). Stockhom: Socialstyrelsen; 2003. Report No: 123:18.

13. Maslach C, Schaufeli WB, Leiter MP. Job burnout. Annu Rev Psychol. 2001;52:397-422.

14. Swedish Institute for Health Economics. EuroQol Group. 2008. Accessed on Feb 10, 2009. Available from: http://www.ihe.se/english/ euroqol.htm.

15. Shirom A. Burnout in work organisations. In: Cooper C, Robertson I, editors. International Review of Industrial and Organizational Psychology. New York: John Wiley and Sons; 1989. p. 25-48.

16. Larsen DL, Attkisson CC, Hargreaves WA, Nguyen TD. Assessment of client/patient satisfaction: development of a general scale. Eval Program Plan. 1979;2(3):197-207.

17. Perski A, Grossi G. [Treatment of patients on long-term sick leave because of stress-related problems. Results from an intervention study]. Lakartidningen. 2004;101(14):1295-1298. 
18. Soares JJ, Grossi G, Sundin O. Burnout among women: associations with demographic/socio-economic, work, life-style and health factors. Arch Womens Ment Health. 2007;10(2):61-71.

19. Stenlund T, Ahlgren C, Lindahl B, et al. Patients with burnout in relation to gender and a general population. Scand J Public Health. 2007;35(5):516-523.
20. Erlandsson LK, Eklund M. The relationships of hassles and uplifts to experience of health in working women. Women Health. 2003;38(4): 19-37.

21. Perski A. [Rehabilitation of stress-related diseases goes on different phases and is often long-lasting]. Lakartidningen. 2004;101(14): 1292-1294.

\section{Publish your work in this journal}

The Journal of Multidisciplinary Healthcare is an international, peerreviewed open-access journal that aims to represent and publish research in healthcare areas delivered by practitioners of different disciplines. This includes studies and reviews conducted by multidisciplinary teams as well as research which evaluates the results or conduct of such teams or healthcare processes in general. The journal covers a wide range of areas and welcomes submission from practitioners at all levels, from all over the world. The manuscript management system is completely online and includes a very quick and fair peer-review system. Visit http://www.dovepress.com/testimonials.php to read real quotes from published authors.

Submit your manuscript here: http://www.dovepress.com/journal-of-multidisciplinary-healthcare-journal 